\title{
BIM Methodology and Tools Implementation for Construction Companies (GreenBIM Project)
}

\author{
Claudio Mirarchi, Caterina Trebbi, Sonia Lupica Spagnolo, Bruno Daniotti, \\ Alberto Pavan and Domenico Tripodi
}

\begin{abstract}
Building Information Modelling (BIM) is recognized as one of the leading innovations in the construction sector. However, some studies highlight how BIM implementation is lagging behind in small and medium enterprises (SMEs). Moreover, the majority of the research is focused on the construction phase and there is a need for further studies able to demonstrate the possibilities associated with the introduction of BIM in construction companies. This paper presents the first set of results from the GreenBIM project focused on the development of a BIM implementation framework from SMEs in the construction sector. In this context, the paper focuses on the quantity estimation starting from building information models analyzed by the construction company.
\end{abstract}

Keywords Small and medium enterprises (SMEs) $\cdot$ Building information modelling $(\mathrm{BIM}) \cdot$ Quantity estimation $\cdot$ Quantity take off $(\mathrm{BIM}) \cdot$ Cost estimation

\section{Introduction}

Building Information Modelling (BIM) is nowadays recognized as one of the leading innovations in the Architecture, Engineering, Construction, Owner and Operator (AECOO) sector. BIM can be seen from different perspectives, interpreting its nature from the technological side as a tool or from the management side, identifying its introduction as a process shift (Jernigan 2007; Volk et al. 2014). The introduction of BIM requires an analysis of the context of application and the strategies adopted to optimize the implementation process can change according to a company's size, its geographical localization, business model, etc. Moreover, it is crucial to consider the societal impact related to the introduction of new technologies and processes

C. Mirarchi $(\varangle) \cdot$ C. Trebbi · S. Lupica Spagnolo · B. Daniotti · A. Pavan

Architecture, Built Environment and Construction Engineering-ABC Department, Politecnico di Milano, Milan, Italy

e-mail: claudio.mirarchi@polimi.it

D. Tripodi

GreenBIM, Reggio Calabria, Italy

B. Daniotti et al. (eds.), Digital Transformation of the Design, Construction and Management Processes of the Built Environment, Research for Development, https://doi.org/10.1007/978-3-030-33570-0_18 
(Mirarchi 2018). To provide a fertile environment to push the implementation of $\mathrm{BIM}$ in the construction industry, it is critical to involve the highest number of organizations in the construction chain. The market configuration in the construction sector (as well as in other ones (OECD 2000)) is characterized by a majority of small and medium enterprises (SMEs). This configuration is not related to a specific country, but it is common for the sector. For example, in Italy around $96 \%$ of the construction companies have less than nine employees (ANCE 2017), in the UK 93\% have less than 13 employees (DTI UK 2006), and in France (all sectors combined) 98.8\% of companies are SMEs (Tranchant et al. 2017).

Several studies in the literature explored the possible benefits related to the use of $\mathrm{BIM}$ in the construction sector. However, most of the existing studies are related to big and/or complex projects and focused on the design phase. Thus, several studies highlighted the lack of research for the SMEs and how SMEs are lagging behind in the adoption of BIM and in general in the implementation of new digital technologies along the lines of the industry 4.0 paradigm (Hosseini et al. 2016; Lam et al. 2017; Li et al. 2019).

The GreenBIM project (under development and in collaboration with the construction company Berna Costruzioni) is based on a practical approach to explore the implementation process of BIM in small and medium construction companies. The research is focused on two areas that still need to be broadly explored that are (a) the implementation process for SMEs and (b) the analysis of benefits and challenges in BIM implementation in the construction companies (i.e. in the construction and maintenance phase). With regards to the barriers in BIM implementation for SMEs explored in previous studies and presented in the next section, the study aims to provide a structured process to facilitate the diffusion of a shared implementation approach that can remove or at least reduce the impact of existing barriers demonstrating the effectiveness of BIM and how to work to achieve the required objectives. This paper presents the state of the art of the project exploring the results reached in the first stage of the study and provides the overview of future research actions.

The rest of the paper is organized as follows. The background section provides a brief summary of the existing studies in BIM implementation for SMEs. It also contains an introduction about the quantity of surveying activities which represent one of the main aims for the construction company in the integration of BIM. The implementation process section describes the activities and the organization structure proposed in the BIM implementation for construction companies focused on a specific objective, i.e., the quantity take off (QTO). Finally, the conclusion section summarizes the results of the research carried out and discusses future activities for the work. 


\section{Background}

\subsection{BIM in Small and Medium Enterprises}

SMEs are usually defined according to their staff headcount, their turnover and/or their balance sheet total. In the European context a company is defined as SME if the staff headcount is under 250 and the turnover is under 50 million euros or the balance sheet total in under 43 million euros (European Union 2003). As already mentioned in the introduction, SMEs constitute most of the companies in the construction sector and their involvement in BIM implementation is crucial to guarantee communication between all parties involved in the construction process and thus define effective collaborative approaches.

However, the introduction of new technologies in SMEs is limited by several barriers. According to their limited investment capacity, SMEs are inclined to adopt consolidated and reliable methods that can guarantee a return on investment (ROI) (Poirier et al. 2015). The absence of practical evidence capable of demonstrating an effective ROI in BIM implementation is one of the main barriers in BIM adoption for SMEs (Hosseini et al. 2016). Li et al. (2019) identified six critical factors and challenges for BIM adoption in SMEs, namely: limited resources, collaboration challenges, lack of BIM awareness, legal disputes and uncertainties in policies, difficulties in meeting SMEs' needs and concerns about data and information. On the other hand, Hosseini et al. (2016) argued that the lack of awareness is no longer a barrier in SMEs in the Australian areas. Malacarne et al. (2018) identified in the lack of standardization a critical barrier which is also limiting the development of effective tools for the industry. In this picture, the proposed research will provide a possible path to follow in the BIM implementation and will demonstrate the benefits related to the use of BIM in construction companies limiting the above-mentioned issues. The results of the project will pave the way for BIM implementation in SMEs reducing the required investments (costs) thanks to a defined and tested roadmap and demonstrating the quantitative returns (ROI) in the investments on BIM adoption.

\subsection{Cost Estimating in BIM}

Cost estimating is a fundamental activity in construction projects. Focusing on construction companies, this activity is critical in the development of their business and it is directly related to the estimation of the resources required for the construction process (e.g., bricks, concrete, workforce, etc.). Some studies demonstrated the benefits of using BIM in the early phases of the construction process to improve the effectiveness of cost estimating activities (Valentini et al. 2017). On the other hand, BIM can support cost estimation activities in the other phases of the project as well providing precise quantity analysis and guaranteeing coherence between the design configuration and quantity estimation. Nevertheless, the information embedded in 
building information models are not sufficient to provide a cost estimate and the quantities obtained from models need to be combined with other information (Wu et al. 2014). On the one hand this activity requires the translation of the geometrical information contained in a model into geometrical information that is coherent with the estimation procedure (Ma et al. 2016). On the other hand, it requires the introduction of knowledge derived from the construction company that can translate the model quantity into quantities of materials, workforce, etc., and consequently into costs.

\subsection{Implementation Process}

BIM implementation in the construction sector companies, whether big or not, requires an articulated action considering among other elements the societal, market and technical context of application, the organizational structure of the company, the knowledge and skills of the personnel, the investment capacity and of course the objectives of the implementation. The main national standards and guidelines related to BIM (e.g., (American Institute of Architects 2013; BSI 2013; BIMForum 2015; UNI 2017)) are usually focused on the specific project and not on the organization. However, the structure of the documents required in the BIM process such as the employer information requirements (EIR) and the BIM execution plan (BEP) express the need to define a process at the organizational level that can be declined according to the specific needs of each project. This vision has been materialized in ISO 19650 part 1 (ISO 2018) where the concept of organizational information requirements (OIR) is introduced representing the information requirements defined according to organizational objectives. Even if not identified in the standard, it is clearly necessary to define not only the requirements but also the way to satisfy these requirements when the actions and the processes are developed directly in the organization. Hence, the BIM implementation process requires the clear identification of the objectives of the organization and the consequent planning of the actions to satisfy these requirements. In general, the objectives of construction companies are related to the need of increasing their productivity (reducing wastes, improving the quantity estimation activities, reducing reworks, etc.) and to the possibility of exploring new business models using innovative technologies, the development of new services, etc. While the GreenBIM project considers the overall picture, this paper presents a specific part of the research that is the definition of structured processes to use the building information models in the quantity estimation activities optimizing the integration between the construction companies' knowledge and the information contained in models.

BIM sees in the development of a shared collaboration environment commonly identified as the common data environment (CDE) (BSI 2007, 2013) one of its core principles. This environment is usually identified as a cloud where all the interested subjects can collaborate and share information throughout the construction process. However, even in the case of a perfect circular approach (which today is still not 
possible due to IT and contractual issues) there is always the need to check and guarantee the quality of the information used as input for the development of subsequent phases of the process. This leads to the need of defining specific requirements related to the development of information models and to check the quality of these models to guarantee the correct development of future activities. The quality of the information provided to the construction company has long been studied as one of the main areas of value loss in the construction process. Discrepancies between information in different documents, difficulties in the interpretation of the design, etc. are only a few examples. The use of BIM can limit these issues creating a model which, by simulating the actual building (or the one that will be constructed) and creating a CDE where all the information is coordinated and related, is able to avoid incoherence between project documents. However, on the one hand the use of BIM can reduce the proliferation of errors in the process. On the other hand, it introduces new needs in terms of data quality requiring a different approach and different competencies in the evaluation of the quality of the information generated and communicated during the process.

Hence, before starting any quantity estimation activity a quality check is required according to the organization requirements defined for the specific use of the information model. This checking activity can be synthesized in two main areas i.e. clash detection and information checking. The first activity must be structured according to the specific needs of the organization and can be organized according to a matrix where the elements that must be checked and those that do not need to be evaluated are highlighted (Table 1).

The translation between models and construction companies' resources is of crucial importance. The model developed by the designer is usually limited in terms of both detailed quantity information and construction site context. As a consequence, the quantity take-off application requires the identification of rules capable of translating the geometrical quantities provided by the models into real geometrical quantities that can reflect the needs of construction companies in their construction activities. Unfortunately, interoperability issues can hinder a fluent process requiring the precise definition of information flows where the output of one phase represents the input of the next one. Thus, starting from the information model defined during the design phase, the construction company needs to introduce its own expertise in the model to obtain the quantity take off model (Fig. 1).

The QTO activity can be developed according to different processes. On the one hand, if there is coherence between the modelling instrument used by the design team and those used by the construction company it is possible to define a direct connection through plug-ins or other direct relations between the geometrical information model and the QTO one. On the other hand, if the instruments are not compatible, it is possible to identify a specific translation of the design model using the IFC format. Nevertheless, the use of IFC requires a specific definition of the information to be exported and the specific analysis on the way in which the geometries are exported from the native model to the IFC one. 
Table 1 Example of clash detection matrix

\begin{tabular}{|c|c|c|c|c|c|c|c|c|c|c|c|c|}
\hline \multirow[t]{2}{*}{ Models } & \multirow[b]{2}{*}{ Classes } & \multicolumn{7}{|c|}{ Arc Model } & \multicolumn{4}{|c|}{ Str Model } \\
\hline & & $\mathrm{Ce}$ & Dr & $\mathrm{Sl}$ & $\mathrm{Ra}$ & St & Wa & Wd & $\mathrm{Sl}$ & St & $\mathrm{Pi}$ & $\mathrm{Be}$ \\
\hline \multirow{7}{*}{$\begin{array}{l}\text { Arc } \\
\text { Model }\end{array}$} & $\mathrm{Ce}$ & & & & & & & & & & & \\
\hline & Dr & & & & & & & & & & & \\
\hline & $\mathrm{Sl}$ & & & & & & & & & & & \\
\hline & $\mathrm{Ra}$ & & & & & & & & & & & \\
\hline & St & & & & & & & & & & & \\
\hline & $\mathrm{Wa}$ & & & & & & & & & & & \\
\hline & $\mathrm{Wd}$ & & & & & & & & & & & \\
\hline \multirow{4}{*}{ Str Model } & $\mathrm{Sl}$ & & & & & & & & & & & \\
\hline & $\mathrm{St}$ & & & & & & & & & & & \\
\hline & $\mathrm{Pi}$ & & & & & & & & & & & \\
\hline & $\mathrm{Be}$ & & & & & & & & & & & \\
\hline \multicolumn{13}{|l|}{$\begin{array}{l}\text { Legend } \\
\text { Ce: Ceilin } \\
\text { Beams. } \\
\text { Arc: Arch }\end{array}$} \\
\hline
\end{tabular}

Once the QTO model is created, this model needs to be integrated with the history of the construction company which can be codified through an ERP (Enterprise Resource Planning). This stage, which is the integration process between the QTO model and the ERP, will be explored through future activities of the project.

\section{Conclusion}

This paper presented a first analysis of the information requirements relating to a specific use of building information models in construction companies, that is, the QTO operation required to pave the way for the definition of the resources for construction activities and consequently their costs. In this context the article proposed an analysis of the existing literature relating to the introduction of BIM in SMEs focusing on the need to provide effective means to help these companies in the digital transition. Starting from the results presented in this paper the GreenBIM project 
Fig. 1 Information flow from the (geometric) information model to the quantity and costs estimation models

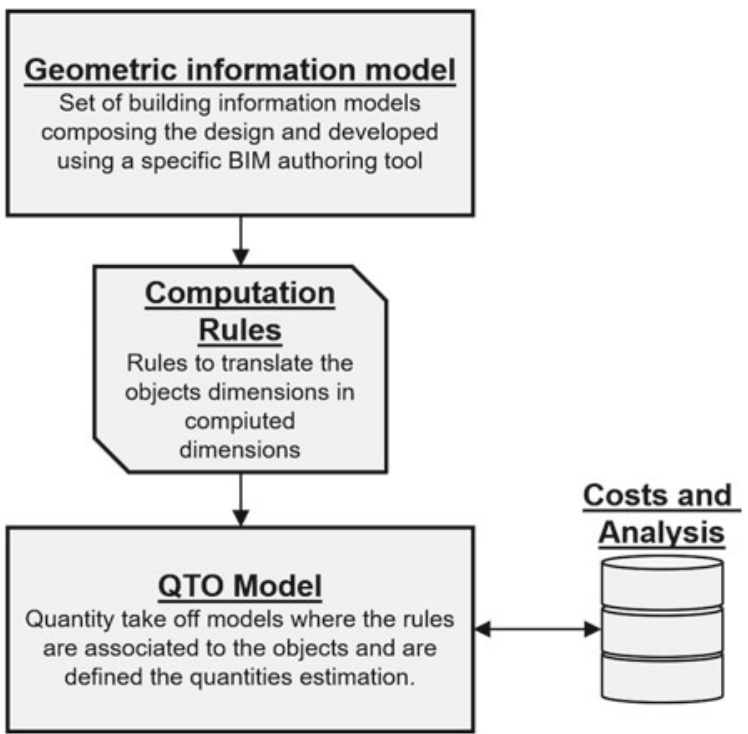

saw the development of a structured process to integrate the QTO model into the construction company database (ERP) in order to match the expertise of the company with the information derived from the information models. Moreover, the project aims to explore the information requirements related to the management of the asset to promote the development of new services according to the maintenance needs and management in the use phases of the final products (buildings, infrastructures, etc.).

\section{References}

American Institute of Architects (2013) Digital practice documents - guide, instructions and commentary. AIA guidelines, pp 1-62

ANCE (2017) Osservatorio congiunturale sull'industria delle costruzioni

BIMForum (2015) Level of development specification 2015

BSI (2007) BS 1192:2007, collaborative production of architectural, engineering and construction information-Code of practice. The British Standards Institution, UK

BSI (2013) PAS 1192-2:2013, Specification for information management for the capital/delivery phase of construction projects using building information modelling. The British Standards Institution, UK

DTI UK (2006) Construction statistic annual, London

European Union (2003) Commission recommendation of 6 May 2003 concerning the definition of micro, small and medium-sized enterprises. Off J Eur Union. https://eur-lex.europa.eu/legalcontent/EN/TXT/PDF/?uri=CELEX:32003H0361\&from=EN

Hosseini MR et al (2016) BIM adoption within Australian small and medium-sized enterprises (SMEs): an innovation diffusion model. Constr Econ Build 16(3):71-86. https://doi.org/10.5130/ ajceb.v16i3.5159 
ISO (2018) ISO 19650-1—Organization of information about construction works-Information management using building information modelling_-Part 1: concepts and principles

Jernigan F (2007) Big BIM, little BIM: the practical approach to building information modeling; integrated practice done the right way. 1st edn. 4Site Press

Lam TT, Mahdjoubi L, Mason J (2017) A framework to assist in the analysis of risks and rewards of adopting BIM for SMEs in the UK. J Civ Eng Manag 23(6):740-752. https://doi.org/10.3846/ 13923730.2017.1281840

Li P et al (2019) Critical challenges for BIM adoption in small and medium-sized enterprises: evidence from China. Adv Civ Eng 2019. https://doi.org/10.1155/2019/9482350

Ma Z, Liu Z, Wei Z (2016) Formalized representation of specifications for construction cost estimation by using ontology. Comput-Aided Civ Infrastruct Eng 31(1):4-17. https://doi.org/10.1111/ mice. 12175

Malacarne $\mathrm{G}$ et al (2018) Investigating benefits and criticisms of BIM for construction scheduling in SMEs: an Italian case study. Int J Sustain Dev Plan 13(1):139-150. https://doi.org/10.2495/ SDP-V13-N1-139-150

Mirarchi C (2018) A spatio-temporal perspective to knowledge management in the construction sector. In: New frontiers of construction management workshop. Ravenna, Italy

OECD (2000) Small and medium-sized enterprises: local strength, global reach. Policy Brief. https:// doi.org/10.1177/0022146511418950

Poirier E, Staub-French S, Forgues D (2015) Embedded contexts of innovation. Constr Innov 15(1):42-65

Tranchant A, Beladjine D, Beddiar K (2017) BIM in French smes: from innovation to necessity. WIT Trans Built Environ 169:135-142. https://doi.org/10.2495/BIM170131

UNI (2017) UNI 11337- 1-Building and civil engineering works-Digital management of the informative processes-Part 1: models, documents and informative objects for products and processes, Italy

Valentini V, Mirarchi C, Pavan A (2017) Comparison between traditional and digital preliminary cost-estimating approaches. Innov Infrastruct Solut. (Springer International Publishing), 2(1):18. https://doi.org/10.1007/s41062-017-0066-7

Volk R, Stengel J, Schultmann F (2014) Building information modeling (BIM) for existing buildings-Literature review and future needs. Automation in construction, vol 38. Elsevier B.V., pp 109-127. https://doi.org/10.1016/j.autcon.2013.10.023

Wu S et al (2014) A technical review of BIM based cost estimating in UK quantity surveying practice, standards and tools. J Inf Technol Constr 19(December):535-563

Open Access This chapter is licensed under the terms of the Creative Commons Attribution 4.0 International License (http://creativecommons.org/licenses/by/4.0/), which permits use, sharing, adaptation, distribution and reproduction in any medium or format, as long as you give appropriate credit to the original author(s) and the source, provide a link to the Creative Commons license and indicate if changes were made.

The images or other third party material in this chapter are included in the chapter's Creative Commons license, unless indicated otherwise in a credit line to the material. If material is not included in the chapter's Creative Commons license and your intended use is not permitted by statutory regulation or exceeds the permitted use, you will need to obtain permission directly from the copyright holder.

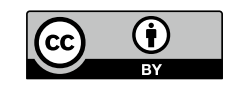

